\title{
Optimal power flow for power system interconnection considering wind power plants intermittency
}

\author{
Willy Akbar Ajami ${ }^{\mathrm{a}, \mathrm{b}, *}$, Ardiaty Arief ${ }^{\mathrm{a}, \mathrm{b}}$ and Muhammad Bachtiar Nappu ${ }^{\mathrm{a}, \mathrm{b}}$ \\ ${ }^{a}$ Centre for Research and Development on Energy and Electricity, Hasanuddin University, Makassar 90245, Indonesia \\ ${ }^{b}$ Power and Energy Systems Research Group, Department of Electrical Engineering, Faculty of Engineering, Hasanuddin \\ University, Gowa 92119, Indonesia
}

\begin{abstract}
The rise of global warming issues and limitation of fossil resources encourages a large number of power plant construction generated by renewable energy. One of the promising renewable energy power generation is the wind power plant. However, the variable of wind speeds may cause problems to its management system and power dispatch of the power grid. The fluctuation of energy demand and wind speed are the main issues regarding the wind power plants (WPP) integration into interconnected power systems. Optimal power flow (OPF) method will determine the optimal operating conditions of the electric network that experiences physical and operational barriers. Factors that determine the optimal point are formulated based on the optimization algorithm method. The primary purpose of the method is to specify the settings of the OPF variable controls and systems of equations that optimize the value function of the objective. The selection of this function should be analyzed carefully based on the electrical power system's technical and economical aspects. Currently in Indonesia, 70 MW capacity of WPP have been built in the Sidrap Regency in the Southern Sulawesi power system and this WPP will be integrated with other thermal generations in the interconnected power system to supply a 1050-1100 MW maximum load. This study evaluates the WPP's output considering the WPP intermittency constraint (the various wind speed) then assesses the optimal power flow results for the Southern Sulawesi case.
\end{abstract}

Keywords: integrated power systems; intermittency; optimal power flow; wind power plant

\section{Introduction}

The rise of global warming issues and limitation of fossil resources encourages a large number of power plant construction generated by renewable energy. One of the promising renewable energy power generation is the wind power plant. Wind power plants (WPPs) are environmentally friendly and has a promising low cost power generation.

At the moment, wind energy is one of the alternative energy sources that has become a new consideration for power generation resources. However, the variable of wind speeds may cause problems to its management system and power dispatch of the power grid. The fluctuation of energy demand and wind speed are the main issues regarding the WPP integration into the interconnected power system.

In the process, integrating WPPs into the system provides a new challenge in the economic dispatch due to the output that depends on natural conditions [1,2]. Optimal Power Flow (OPF) method will determine the optimal operating conditions of the electric network that experiences physical and operational barriers [3 - 7]. Factors which are the optimal point will be formulated and solved by using optimization algorithm accordingly. The primary purpose of the method is to specify the settings of the

\footnotetext{
* Manuscript received October 4, 2018; revised March 15, 2019.

Corresponding author. Tel.: +0-000-000-0000 ; E-mail address: wawillyakbar@gmail.com.

doi: $10.12720 /$ sgce.8.3.372-376
} 
OPF variable controls and systems of equations that optimize the value function of the objective. The selection of this function should be analyzed carefully based on the electrical power system's technical and economical aspects.

There has been many researches on OPF considering WPP's integration. Research in [8] explained about how Demand Dispatch (DD) could improvise the system's ability to handle wind intermittency with probabilistic forecast method. Authors in [9] proposed probability density function (PDF) method to solve OPF constraints in the IEEE 30 bus and the IEEE 118 bus illustrations. Biogeography based optimization (BBO) algorithm was compared with Monte Carlo method (MCS) to find the better algorithm for multi objective OPF in [10]. The study in [11] defined about how non-dominated sorting genetic algorithm (NSGA) method numerically could solved OPF constraints more rational and effective. How group search optimization (GSO) could solve multi objective OPF (MO-OPF) better than Monte Carlo method (MCS) was explicated in [12]. The investigation in [13] mentioned about how interval optimization (PIO) method could solve wind power OPF (WP-OPF) on a numerical test in the IEEE 30 bus system.

Currently in Indonesia, 70 MW capacity of WPPs have been built in the Sidrap Regency in the Southern Sulawesi power system and this WPP will be integrated with other thermal generations in the interconnected power system to supply a 1050-1100 MW maximum load [14]. More details of the Southern Sulawesi power system can be found in [15-17]. The power utility will need to plan the dispatch for a wide range of wind speed and various loads. Therefore, the OPF study for the Southern Sulawesi power system is important to maintain the system's stability and reliability. This study evaluates the WPP's output considering the WPP intermittency constraint (the various wind speed) then assesses the optimal power flow results for the Southern Sulawesi case.

\section{The Proposed Methodology}

OPF aims to minimize fuel costs by not breaking the generator constraints. It can be formulated as follows:

Minimize $F=\sum_{i=1}^{N G} F_{i}\left(P_{g i}\right)$

Where, $F$ is the total fuel costs and the $F_{i}$ is the fuel cost of the $i^{\text {th }}$ power station. Limitation of the power balance equations described equality as,

$$
\begin{aligned}
& P_{g i}-P_{d i}=\sum_{j=1}^{N}\left|V_{i}\right|\left|V_{j}\right|\left|y_{i j}\right|\left(\theta_{i j}-\delta_{i}+\delta_{j}\right) \quad i=1, \ldots, N \\
& Q_{g i}-Q_{d i}=\sum_{j=1}^{N}\left|V_{i}\right|\left|V_{j}\right|\left|y_{i j}\right|\left(\theta_{i j}-\delta_{i}+\delta_{j}\right) \quad i=1, \ldots, N
\end{aligned}
$$

Where, $P_{g i}$ is the total of active power generation of the $i^{\text {th }}$ bus, $P_{d i}$ is the total active power load of the $i^{\text {th }}$ bus, $Q_{g i}$ is the total of reactive power generation of the $i^{\text {th }}$ bus, $Q_{d i}$ is the total of reactive power load of the $i^{\text {th }}$ bus, $\left|V_{i}\right|$ is the voltage magnitude of the $i^{\text {th }}$ bus, $\left|V_{j}\right|$ is the voltage magnitude of the $j^{\text {th }}$ bus, $\theta_{i j}$ is the admittance angle between $i^{\text {th }}$ and $j^{\text {th }}$ buses, $\delta_{i}$ is the voltage angle of the $i^{\text {th }}$ bus, $\delta_{j}$ is voltage angle of the $j^{\text {th }}$ bus.

\subsection{Inequality constraints on the systems}

\subsubsection{Generation constraints}

The real power output generation, voltage and reactive power output are limited by their minimum and 
maximum limits as follow,

$$
\begin{array}{ll}
P_{g i}^{\min } \leq P_{g i} \leq P_{g i}^{\max } & i=1, \ldots, N G \\
Q_{g i}^{\min } \leq Q_{g i} \leq Q_{g i}^{\max } & i=1, \ldots, N G \\
|V|_{g i}^{\min } \leq|V|_{g i} \leq|V|_{g i}^{\max } & i=1, \ldots, N G
\end{array}
$$

Where, $P_{g i}^{\min }$ and $P_{g i}^{\max }$ are the minimum and maximum real power generation of the $i^{\text {th }}$ generator bus, respectively, $Q_{g i}^{\min }$ and $Q_{g i}^{\max }$ are the minimum and maximum reactive power generation of the $i^{\text {th }}$ generator bus, respectively, $|V|_{g i}^{\min }$ and $|V|_{g i}^{\max }$ are the minimum and maximum voltage magnitude of the $i^{\text {th }}$ generator bus, respectively.

\subsubsection{Security limits that covered voltage magnitude of the load bus}

The voltage magnitude constraints of the load buses are as follow,

$$
|V|_{L i}^{\min } \leq|V|_{L i} \leq|V|_{L i}^{\max } \quad i=1, \ldots, N L
$$

Where $|V|_{L i}^{\min }$ and $|V|_{L i}^{\max }$ are the minimum and maximum magnitude voltage of the $i^{\text {th }}$ load bus.

\section{Result and Analysis}

In this study, wind speed at the Sidrap Regency was downloaded from NASA [18]. Fig 1 describes wind speed fluctuations from January 2017 until December 2017 which determined that the maximum wind speed is $5.8 \mathrm{~m} / \mathrm{s}$, the average is around $3.5 \mathrm{~m} / \mathrm{s}$ and the minimum is $2.5 \mathrm{~m} / \mathrm{s}$ with the related WPPs output power. The highest WPP output power is $5.82 \mathrm{MW}$ when the wind speed position is $5.8 \mathrm{~m} / \mathrm{s}$ and its lowest output is $0.56 \mathrm{MW}$ when the wind speed is less than $2.5 \mathrm{~m} / \mathrm{s}$.

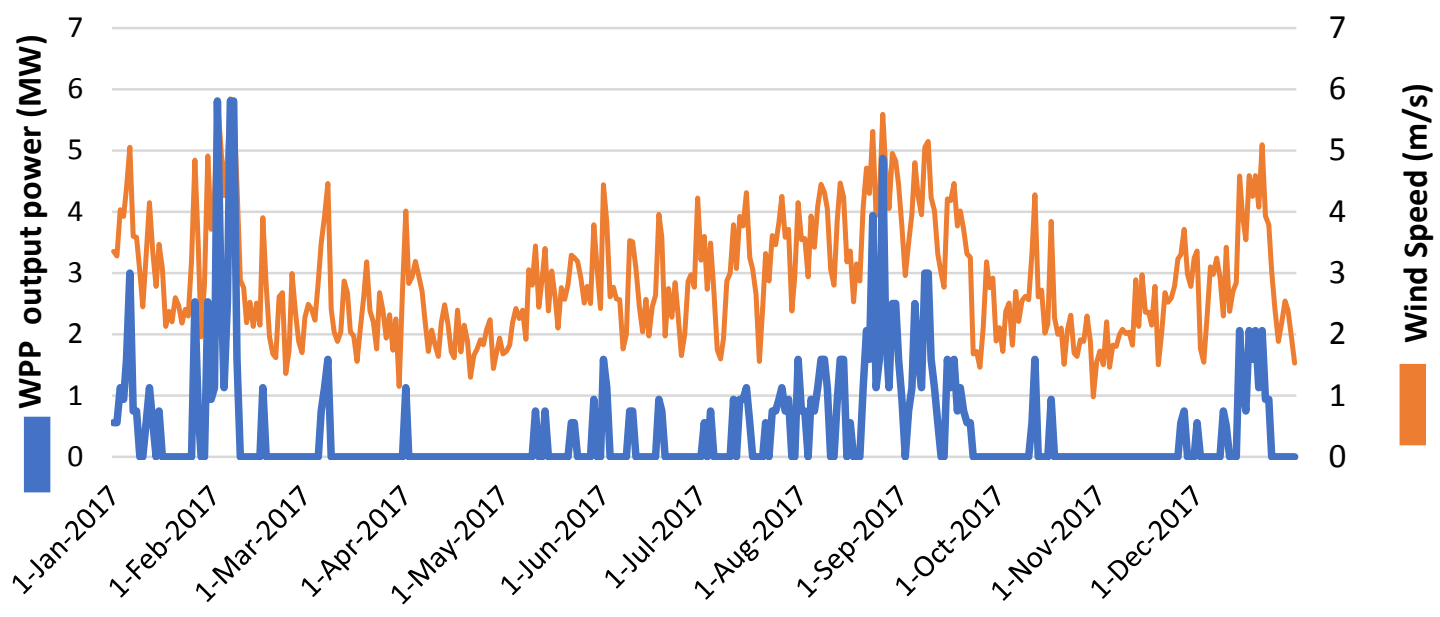

Fig. 1. Wind speed and related WPP's output for Sidrap WPP

Fig. 2 shows the total power generated and power losses of the Southern Sulawesi power systems before and after the integration of the Sidrap WPP if the wind speed is assumed to be at the maximum. Fig. 2 compares the power flow analysis results by conventional power flow (CPF) and OPF analysis which both analysis informs that the integration of the Sidrap WPP can reduce power losses and the total 
power generated. This is because the Sidrap WPP's locations is quite close to the load centre, which is Makassar City. However, the OPF analysis resulted in higher power generated and higher network losses than the CPF analysis results, as this indicates that there might be some main lines that have over capacity condition if it is analysed by using OPF algorithm, hence the OPF program did some redispatching. Therefore, to minimize total power generated and losses, the Southern Sulawesi power systems needs development of new infrastructure that could connect the Sidrap WPP to the load centre, so it can minimize total power generated and power losses and to avoid the system to work in over load conditions.

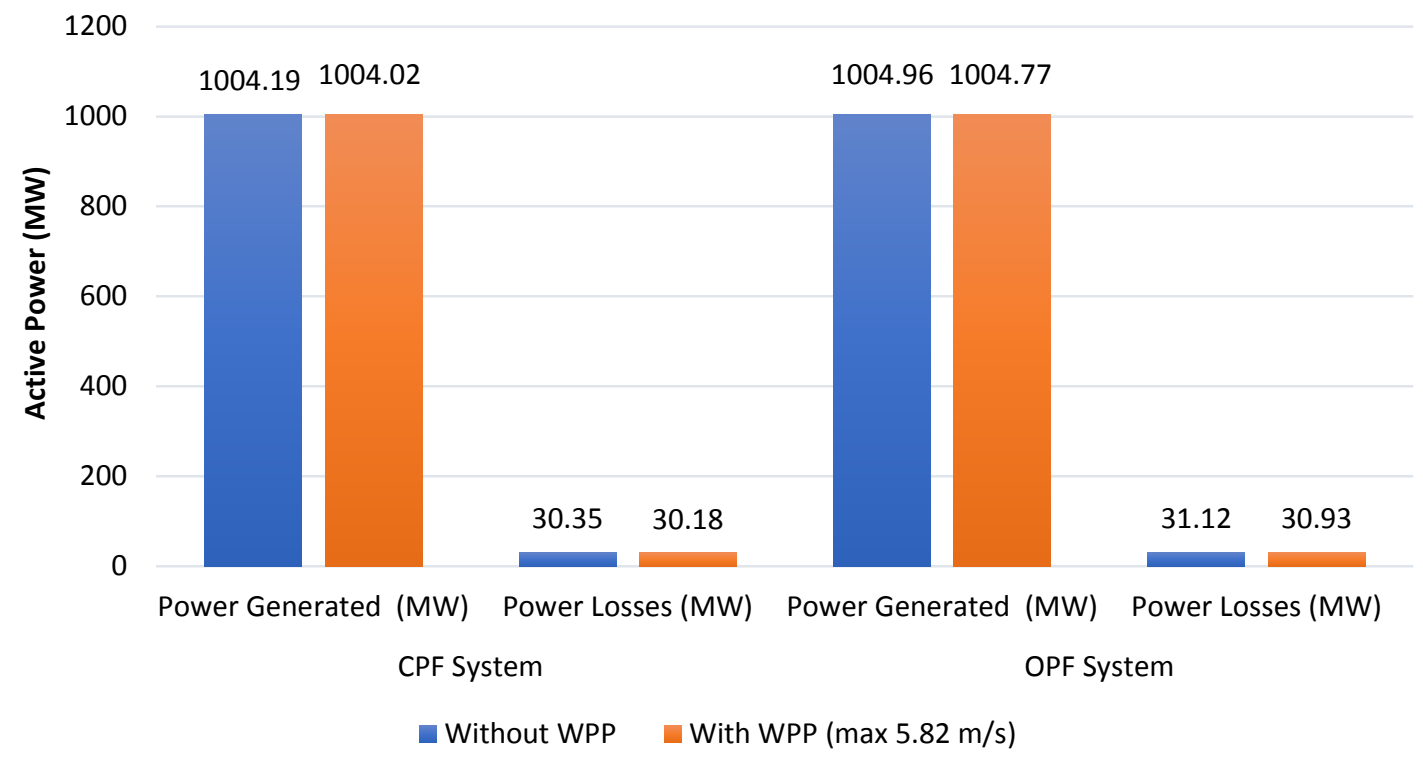

Fig. 2. Power generated and power losses condition with and without WPP

Since WPPs are absorbing reactive power [19], therefore further research in the area of reactive power compensator $[20,21]$ needs to be done to maintain the system's stability.

\section{Conclusions}

Integrating WPP to interconnected power systems is quite challenging because of the wind intermittency that affectsthe WPP output power. The fluctuation of output power itself can be dangerous for power system's stability.

This paper compares the CPF and OPF algorithm with and without WPP integration in the Southern Sulawesi power system in Indonesia. The integration of the Sidrap WPP can decrease total power generation and power losses in the Southern Sulawesi power system if the wind speed is considered to be at the maximum. However, since OPF determined the operating conditions economically and the line capacity, the results indicated the possibility of some transmission lines or substations to have over capacity condition. Furthermore, the planning of new infrastructure should give attention to line capacity and the distance between power plants and load centers.

\section{Acknowledgements}

The authors gratefully acknowledge the Indonesian Ministry of Research, Technology and Higher Education for providing the research grant and support in this work. 


\section{References}

[1] Arief ZY, Dong MB, Nappu, Gallagher M. Under voltage load shedding in power systems with wind turbine-driven doubly fed induction generators. Electric Power System Research, Elsevier, March 2013; 96: 91-100.

[2] Azis F, Arief A, Nappu MB. Fuzzy logic based active power generation dispatching considering intermittent wind power plants output. 2017 International Conference on Control, Electronics, Renewable Energy and Communications (ICCREC), Yogyakarta, 2017: 116-121.

[3] Bachtiar Nappu M, Arief A, Bansal RC. Transmission management for congested power system: A review of concepts, technical challenges and development of a new methodology. Renewable and Sustainable Energy Reviews, 2014; 38: 572580 .

[4] Nappu, Bansal RC, Saha TK. Market power implication on congested power system: A case study of financial withheld strategy. International Journal of Electrical Power \& Energy Systems, 2013; 47: 408-415.

[5] Nappu MB, Arief A. Network losses-based economic redispatch for optimal energy pricing in a congested power system. Energy Procedia, 100: 311-314, 11// 2016.

[6] Nappu MB and Arief A. Economic redispatch considering transmission congestion for optimal energy price in a deregulated power system. in 2015 International Conference on Electrical Engineering and Informatics (ICEEI), 2015: 573-578.

[7] Nappu MB. LMP-lossless for congested power system based on DC-OPF. in Electrical Engineering and Informatics (MICEEI), 2014 Makassar International Conference on, Makassar, SULSEL Indonesia, 26-30 November, 2014, pp. 194-199.

[8] Audun B, Zhi Z, Jianhui W, Jean S, Hrvoje K, Joana M, Ricardo JB, Vladimiro M. Demand dispatch and probabilistic wind power forecasting in unit commitment and economic dispatch: A case study of Illinois. www. sciencedirect.com, 2012.

[9] Shima R, Nima A. "A new optimal power flow approach for wind energy integrated power systems", www. sciencedirect.com, 2012

[10] Shargh SB. Khorshid G, Mohammadi-ivatloo B, Seyedi H, Abapour M. Probabilistic multi-objective optimal power flow considering correlated wind power and load uncertainties. www. sciencedirect.com, 2016

[11] Rui M, Jiaqian Q. Multi-objective Optimal Power Flow of Multiple- Energy System Considering Wind Power Penetration. www.ieee.com, 2017

[12] Shiwei X, Member, IEEE, Xiao L, Ka WC, Member, IEEE, Ming Z, and Gengyin L. Probabilistic Transient Stability Constrained Optimal Power Flow for Power Systems With Multiple Correlated Uncertain Wind Generations. www.ieee.com, 2016.

[13] Chen JJ, Wu QH. Probability Interval Optimization for Optimal Power Flow Considering Wind Power Integrated. www.ieee.com, 2016

[14] EBTKE, WPP Sidrap 70 MW . Available : "http://ebtke.esdm.go.id/post/2016/04/07/1182/pltb.sidrap.70.mw.siap.dibangun

[15] Arief, Ardiaty and Muhammad Bachtiar Nappu. "Voltage drop simulation at Southern Sulawesi power system considering composite load model." in 2016 3rd International Conference on Information Technology, Computer, and Electrical Engineering (ICITACEE). Semarang, Indonesia (2016); 169-172.

[16] Arief A, Muhammad BN, Sitti MR, Mustadir D. Optimal photovoltaic placement at the southern sulawesi power system for stability improvement. in 2017 4th International Conference on Information Technology, Computer, and Electrical Engineering (ICITACEE). Semarang, Indonesia, 19 October: 2017; 87-92.

[17] Nappu, Muhammad B, Muhammad IB, Ardiaty A. Network losses reduction due to new hydro power plant integration. in 2016 3rd International Conference on Information Technology, Computer, and Electrical Engineering (ICITACEE). Semarang, Indonesia (2016); 181-185.

[18] NASA, "Power Data Acces NASA," NASA, [Online]. Available: power.larc.nasa.gov/data-acces-viewer/. [Accessed 15 may 2018].

[19] Hung, Duong Q, Nadarajah M, and Kwang YL. Determining PV penetration for distribution systems with time-varying load models. IEEE Transactions on Power Systems, 2014; 29(6): 3048-3057

[20] Arief, Ardiaty, Antamil, and Muhammad Bachtiar Nappu. An analytical method for optimal capacitors placement from the inversed reduced jacobian matrix. Energy Procedia, 2016; 100: 307-310.

[21] Arief A, Muhammad BN, Antamil. Analytical method for reactive power compensators allocation. International Journal of Technology, 2018; 9(3): 602-612. 